\title{
Erratum: New pre-clotting method for fibrin glue in a non-sealed graft used in an LVAD: the KYO method
}

\author{
Motoyuki Hisagi - Takashi Nishimura • \\ Minoru Ono $\cdot$ Satoshi Gojo $\cdot$ Kan Nawata \\ Shunei Kyo
}

Published online: 14 December 2010

(C) The Japanese Society for Artificial Organs 2010

Erratum: J Artif Organs (2010) 13:174-177

DOI 10.1007/s10047-010-0504-1

In the "Materials and methods" and the "Acknowledgments" sections, a corporate name appeared incorrectly. The correct name is CSL Behring K.K., not CLS Behring K.K.

The online version of the original article can be found under doi:10.1007/s10047-010-0504-1.

M. Hisagi $(\bowtie) \cdot$ T. Nishimura $(\bowtie) \cdot$ S. Gojo $\cdot$ S. Kyo

Division of Therapeutic Strategy for Heart Failure,

Department of Cardio-Thoracic Surgery,

The University of Tokyo, 7-3-1 Hongo,

Bunkyo-ku, Tokyo 113-8655, Japan

e-mail: mhisagi-tky@umin.ac.jp

T. Nishimura

e-mail: takashin-tky@umin.ac.jp

M. Ono - K. Nawata

Department of Cardio-Thoracic Surgery,

The University of Tokyo, 7-3-1 Hongo,

Bunkyo-ku, Tokyo 113-8655, Japan 